the centres; many are seen in peripheral clinics. Similarly, there are disabilities other than neurological ones that require rehabilitation skills and other professionals - not all of them medicalwith such skills.

Elmstead Younger Disabled Unit, Queen Mary's Hospital,

Queen Mary's Hospi
Kent DA14 6LT

\section{Why women are not receiving anti-Rh prophylaxis}

SIR,-I noted with concern Dr P A Gover's claim that women are refusing to receive anti-D immunoglobulin because of the fear of the acquired immune deficiency syndrome (9 May, p 1232).

I have had a number of queries from obstetricians from various parts of Britain about this question, and $I$ have pointed out to them that millions of ampoules of anti-D immunoglobulin have been administered throughout the world and, without doubt, in the past some of it has probably been obtained from virus positive material, but no case of a recipient developing antibodies to human immunodeficiency virus (HIV) has been reported to my knowledge. This is particularly so with regard to intramuscular immunoglobulin, the preparation used in Britain. Not only is all source material tested for antibodies to HIV but the processing of the plasma destroys any viral particles evading this net.

There is no reason, therefore, for mothers to refuse to have anti-D immunoglobulin injections prophylactically. If this fear does become widespread then Dr Gover is correct in stating that the number of unprotected mothers will increase and the encouraging fall in mortality and morbidity due to $\mathrm{Rh}$ haemolytic disease will cease, or even be reversed, which would be not only tragic but unnecessary

\section{A DERRICK TOVEY}

Regional Transfusion Centre,

Leeds LS15 7TW

\section{Mortality from myocardial infarction in different types of hospitals}

SIR,-The observations of Dr Robert Reznik and colleagues in Australia (2 May, p 1121) are of great interest to clinicians and health care planners in Britain. Dr Reznik and coworkers, having stratified the coronary care facilities offered by 18 hospitals into four grades of refinement or complexity, found no difference in overall hospital mortality among patients with myocardial infarction in the four groups. The referral of high risk patients to the more specialised units did not account for the findings. This message is unlikely to surprise many practising doctors who realise that until recently the principal benefit of any coronary care organisation was the provision of immediate resuscitation from ventricular fibrillation.

The practice of coronary care has undoubtedly become over elaborate in some units, with little obvious benefit to the patient. Perhaps the most important practical advance over the past 20 years has been the development of the role of the nurse as a resuscitator who will provide defibrillation with the minimum of delay. It is therefore hardly surprising that the absense of a staff cardiologist or in house cardiac surgical services, coupled with only basic monitoring facilities, did not result in a higher inpatient mortality. What we really need to know is a great deal more about the nursing care that was provided.

Evidently, resuscitation was successful in the "small country district hospital." It seems unlikely that the visiting doctor or general practitioner was well placed to be effective in this respect, and therefore the nurse was clearly the key factor. If patients were resuscitated by nurses the description of nurses as "comparatively inexperienced" requires elaboration. Indeed, without more data with regard to nursing numbers and experience it is impossible to relate this study to our own domestic practice. Nursing statistics are doubly important when attempting to interpret the study's comparison of mortality in general wards with that in units. Unfortunately, however, it would be extremely difficult to interpret this section, even with the extra data, as so much clearly depends on individual hospital admission policies.

Any manager in Britain who is tempted to look covetously at resources now "wasted" on the coronary care unit should reflect that with general medical wards often staffed by only one or two nurses the chances of observing, let alone correcting, cardiac arrest would be remote. Finally, although defibrillation, and to a lesser extent pacing, have been the mainstay of coronary care practice in recent times, the promise of thrombolysis is such that a policy of early admission to hospital and high quality nursing care is likely to be of increasing importance.

\section{B L Pentecost}

General Hospital,

Birmingham B4 6NH

\section{Housing conditions and ill health}

SIR,-Dr Claudia J Martin and colleagues (2 May, p 1125) do not seem to have considered the obvious confounding factor of unemployment in their analysis. This seems particularly surprising as they state that there were no adults (excluding pensioners) in paid employment in $45 \%$ of the households that they studied. Though the evidence that unemployment causes ill health is still sparse, it is clear that unemployment and illness are closely associated in those of working age and their close relatives. . $^{1-5}$

If the authors did test the factor of unemployment but omitted to tell us then we can assume only that they fail to acknowledge its importance. By not testing this factor, however, they have jeopardised the value of their results. No doubt the irony is unintended, but they begin their abstract with the comment: "Lack of empirical evidence that living in damp houses has detrimental effects on health may partly be due to inadequate research." People who live in glass houses (damp or dry) should not throw stones.

NORMAN BEALE

Wiltshire SN11 8NQ

Beale N, Nethercott $S$. Job loss and family morbidity: a study of a factory closure. $7 R$ Coll Gen Pract 1985;35:510-4

2 Linn M, Sandifer R, Stein S. Effects of unemployment on mental and physical health. Am f Public Health 1985;75:502-6.

Moser K, Fox A, Jones D. Unemployment and mortality in the OPCS longitudinal study. Lancet 1984;ii:1324-9.

Warr P. Work, jobs and unemployment. Bulletin of the British Psychological Society 1983;36:305-11.

5 Gravelle H. Does unemployment kill? Abingdon, Oxon: Nuffield Provincial Hospitals Trust, 1985.

AUTHORS' REPLY,-As we indicated in our paper, it is obviously impossible to allow for all confounding factors in assessing the relation between damp housing and health. The role of unemployment, however, should perhaps have been considered more fully as it is quite clear that it is a major cause of ill health.

Certainly, we found that income was inversely related to Nottingham health profile scores-that is, the lowest income group had the worst perceived health. There were, however, no significant differences in physical health between adults living in damp and non-damp houses. Moreover, there were no differences in the unemployment rates between these two groups. We did not, therefore, pursue the importance of unemployment in relation to health differences between adults living in different housing conditions; the effects of housing conditions on the health of adults in this sample would not have been influenced by unemployment, even though unemployment may have had a more global effect on their health.

As far as the health of children is concerned, we have now extended the analysis controlling for the presence of unemployment in the household. The original results (that is, of significant effects of dampness in relation to respiratory and gastrointestinal symptoms) remain unaltered. Dr Beale might, however, be interested to know that one symptom (diarrhoea) showed a significant main effect for unemployment, while two further symptoms (nerves and fever or high temperature) showed an interaction between dampness and unemployment, so that the highest rates were found in damp houses where there was also no one in employment.

Claudia J Martin SONJA M HUNT

Research Unit in Health and Behavioural Change,

University of Edinburgh

Edinburgh EH1 2QZ

Stephen D Platt

MRC Unit for Epidemiological Studies

in Psychiatry,

Royal Edinburgh Hospital,

Edinburgh EH10 5HF

\section{Internal market in the NHS}

SIR,-Scrutator (16 May, p 1298) draws our attention to the vexed question of cross boundary flows and whether this aspect of funding health authorities should be liberalised to provide an internal market system within the National Health Service. Such a system would strengthen the funding of a good department balanced by the decline in a department in a neighbouring district with a lower workload. An internal market would bring real choice and consumerism into the NHS and is arguably the only thing that would make clinical budgeting a worthwhile exercise. I suspect that most consultants would be happy with clinical budgeting if the budget of a department were related to its workload and could thereby be increased by working harder.

An internal market would also take care of regional specialties and regional centres of excellence, which have no special recognition or regional funding. Top slicing would no longer be necessary as patients referred from one health authority to another for specialised treatment would "take with them" an amount of money appropriate to the treatment given.

This sounds like Utopia compared with our present bureaucratic tangle, and we might pause to ask why the NHS Management Board has found it unacceptable when we all thought that the board was introduced to revitalise the NHS and bring into it lessons from private industry. The reason is simple: the management objective is not really to do with efficiency or effectiveness but is fundamentally about control. Clearly, one objective is to obtain as high a level of service as possible for the money concerned, but the overriding objective of a health authority is to keep within its cash limit. Control is therefore the order of the day. Once doctors refer patients to neighbouring authorities and the bill has to be met by the health authority in which the patient lives control is lost. Similarly, 